\title{
MANDATORY NOTIFICATION OF CHILD ABUSE AND NEGLECT: PERSPECTIVES FROM PSYCHOLOGY
}

\author{
ELISE THOMPSON*
}

This comment responds to the primary article by Vanessa Deverson in this volume by giving some insights into the problem of mandatory reporting from the perspective of psychology. Parts I and II provide a survey of the legal and ethical requirements imposed on psychologists to report suspected child abuse and neglect. The article then moves on in Part III to discuss the way that psychologists balance the need to maintain client confidentiality with their duties to report. The article argues that lawyers should have the option to report child abuse and neglect, but warns that, before any reporting of child abuse and neglect can be successful, a vast improvement in the management of notifications is essential.

\section{CONTENTS}

I Legal Reporting Requirements of Psychologists in Australia 141

A South Australia ................................................................ 141

B Tasmania ......................................................................... 141

C Northern Territory ............................................................ 142

D Australian Capital Territory................................................ 142

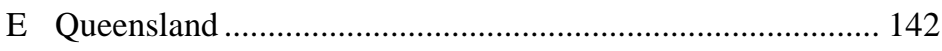

F New South Wales ......................................................... 142

G Victoria and Western Australia ....................................... 142

II Ethical Reporting Requirements for Psychologists ..................... 143

III Confidentiality and Mandatory Reporting ................................. 143

IV Response to Reports ............................................................. 144

$\mathrm{V}$ Conclusion............................................................................ 145

BPsych (Hons) (University of Adelaide); Master of Psychology (Clinical) student, School of Psychology, Social Work and Social Policy, University of South Australia. 


\section{INTRODUCTION}

The conclusion reached in the primary article by Vanessa Deverson is that lawyers should be required to report child abuse and neglect. ${ }^{1}$ Contrary to the current situation, where legal privilege and confidentiality prohibit lawyers from reporting, this article supports the position that, even if lawyers are not legally required to report suspected abuse and neglect, they should, nevertheless, have the option to report. The primary article highlights the devastating impact of child abuse and neglect, and the steps that legislators have taken to curb the incidence in Australia. Part I of this article provides an overview of mandatory reporting of abuse and neglect from the perspective of psychology and outlines the legal requirements imposed on psychologists to report in each state and territory in Australia. The ethical requirements of psychologists to report abuse and neglect is explored in Part II; and Part III explains how psychologists manage the concurrent duties of mandatory reporting and confidentiality. The article concludes by discussing the proper response to mandatory reports and highlights areas for improvement.

\section{LEGAL REPORTING REQUIREMENTS OF PSYCHOLOGISTS IN AUSTRALIA}

In Australia, the legal duties of psychologists to report child abuse or neglect differ between each state and territory. South Australia, Tasmania, the Northern Territory and the Australian Capital Territory are the only places with mandatory reporting requirements that apply specifically to psychologists. In other states, psychologists may be legally required to make a report if they are employed in certain areas. The laws on mandatory notification for psychologists in each state and territory are outlined below.

\section{A South Australia}

In South Australia, under s11 of the Children's Protection Act 1993 (SA), all registered psychologists are mandated to report if, in the course of their work, they have reasonable grounds to suspect that a child is being physically, sexually, emotionally or psychologically abused or neglected.

\section{B Tasmania}

The Children, Young Persons and Their Families Act 1997 states in s 14 that all registered psychologists are required to report if they have a belief, a

\footnotetext{
Vanessa Deverson, 'Child Abuse and Neglect, Mandatory Reporting and the Legal Profession’ (2016) 2 University of South Australia Student Law Review 102.
} 
suspicion on reasonable grounds or knowledge that a child is being physically, sexually, emotionally or psychologically abused, neglected, or exposed to family violence.

\section{Northern Territory}

In the Northern Territory, s 26 of the Care and Protection of Children Act 2007 (NT) requires any person with a belief on reasonable grounds that a child has suffered or may suffer harm or exploitation by being physically, sexually, emotionally or psychologically abused, neglected, or exposed to family violence to make a report. In addition, under s 26 (2), all registered health professionals, which includes psychologists, must report if they have a belief on reasonable grounds that a child has been the victim of a sexual offence and the age difference between the child and the offender is greater than two years.

\section{Australian Capital Territory}

Section 356 of the Children and Young People Act 2008 (ACT), requires registered psychologists to report if during the course of their work they believe on reasonable grounds that a child has experienced or is experiencing sexual or physical abuse.

\section{E Queensland}

In Queensland, under s 365 of the Education (General Provisions) Act 2006 (Qld), employees at any public or independent school are required to report if they reasonably suspect a child has been sexually abused (but not if they suspect neglect or physical, emotional and psychological abuse). In addition, the Child Protection Act 1999 (Qld) s13F, provides that employees in the Department of Communities, Child Safety and Disability Services are also mandated reporters.

\section{F New South Wales}

In New South Wales, under s 27 of the Children and Young Persons (Care and Protection) Act 1998 (NSW), both psychologists who are employed to deliver health care, education (including school psychologists) or children's services, and psychologists who supervise those providing services to children, are required to report if they believe there is a risk of significant harm or abuse.

\section{G Victoria and Western Australia}

Psychologists are not named as mandated reporters in Victoria or Western Australia. 


\section{ETHICAL REPORTING REQUIREMENTS FOR PSYCHOLOGISTS}

In addition to legal duties to report, psychologists also have an ethical requirement to report suspected abuse or neglect. The principles of professional conduct, responsibilities and confidentiality are outlined in the Australian Psychological Society's Code of Ethics, which has been adopted by the Psychology Board of Australia as the profession's ethical code. Under General Principle A: Respect for the rights and dignity of people and peoples, s A.5.2 of the Code states:

Psychologists disclose confidential information obtained in the course of their provision of psychological services only under one or more of the following circumstances:... where there is a legal obligation to do so (or) if there is an immediate and specified risk of harm to an identifiable person or persons that can be averted only by disclosing information. ${ }^{2}$

The Ethical Guidelines that accompany the Code suggest that, before deciding how they will act, psychologists who suspect or have knowledge of child abuse or neglect should consider a series of questions including, among others:

- What is the relevant legislation in this jurisdiction?

- Does the legislation mandate me as a psychologist or in my current position as an employee to report cases of suspected child abuse and neglect?

- Are there any workplace policies and procedures that require me to report suspected child abuse and neglect?

- If I am not mandated/gazetted to report suspected child abuse and neglect, how will the welfare of the child be affected by whatever action I take?

- Have I adequately consulted with a senior colleague? ${ }^{3}$

In deciding to make a notification, psychologists are well supported by the ethical guidelines, and members of the Australian Psychological Society can also obtain advice from their Professional Advisory Service if needed.

\section{CONFIDENTIALITY AND MANDATORY REPORTING}

The establishment and the maintenance of confidentiality between a psychologist and a client are fundamental to professional practice. The statement by Adrienne Lockie that the lawyer-client relationship 'relies on

Australian Psychological Society, Code of Ethics (2007, Melbourne, Vic) 15.

3 Australian Psychological Society, Guidelines on Reporting Abuse and Neglect, and Criminal Activity, (2014, Melbourne, Vic) 147, 150. 
confidentiality to a greater extent than other professions ${ }^{4}$ is simply not true. As shown by mandatory reporting requirements for psychologists, any reliance on confidentiality by a profession is not a valid reason to stop a practitioner from reporting suspected child abuse or neglect. Lockie also raises concerns that the initial meeting would need to be taken up by explaining complex laws rather than building a relationship. This is again refuted in the example set by psychology. In initial consultations with clients, explaining the limits to confidentiality takes less than five minutes. ${ }^{5}$ Clients are given the opportunity to ask any questions that they have about this, and then the rest of the session proceeds. This takes up very little additional time, and clients understand confidentiality and its limits without the explanation of complex laws. ${ }^{6}$

\section{RESPONSE TO REPORTS}

It has been documented that mandatory reporting of child abuse and neglect is effective in identifying cases that would otherwise have not been detected. ${ }^{7}$ However, having mandatory reporting requirements in place is effective only if those notifications result in an appropriate response from child protection agencies. In 2014-15, 48 per cent of all child protection notifications made in South Australia were assessed as 'notifier only concerns' ('NOCs'), which means that the notification was insufficient or vague, the notifier lacked credibility or the notification did not meet the definition of abuse or neglect. ${ }^{8}$ and therefore no intervention was necessary. However, when a sample of 20 of the notifications classified as NOCs was examined as part of the Child Protection Systems Royal Commission, they found that: 15 of the 20 should have been responded to within a week; a further three required a less urgent response; while only two notifications would not have required a response. ${ }^{9}$

4 Adrienne Lockie, 'Salt in the Wounds: Why Attorneys Should Not be Mandated Reporters of Child Abuse' (2006) 36 New Mexico Law Review 125, 140.

5 See, eg, Mary Fisher who has constructed an ethical practice model that can accommodate advising clients such matters as mandatory reporting in 'Protecting Confidentiality Rights: The Need for an Ethical Practice Model' (2008) 63(1) American Psychologist 1.

6 Ibid.

7 South Australia, Child Protection Systems Royal Commission, The Life they Deserve: Child Protection Systems Royal Commission Report, (2016) 117.

$8 \quad$ Ibid 119

9 Ibid 122 
It is evident that the response to notifications is seriously lacking, and it is in this respect that mandatory reporting has the potential to do harm. If a psychologist is mandated to make a notification about suspected child abuse, they can inform the child's caregiver of the course of action they are required to take. This could result in the caregiver losing trust in the psychologist, the destruction of the therapeutic relationship, and ultimately the caregiver and child not returning for further treatment. ${ }^{10}$ If the notification is then screened as a NOC and no further action is taken by the child protection agency, then the process of mandated reporting has been of no benefit to, and indeed, has indirectly harmed the child, who could then be deprived of the opportunity to receive psychological intervention due to the caregiver's loss of trust in the psychologist. ${ }^{11}$ Therefore, if mandatory reporting of child abuse and neglect is to be successful, a vast improvement in the management of notifications is essential.

\section{CONCLUSION}

This article has provided an overview of mandatory reporting of child abuse and neglect in Australia from the perspective of psychology. It has demonstrated that it is possible for members of a profession like psychology, which relies on confidentiality between a client and the professional practitioner, to navigate a path between that duty of confidentiality and a mandated duty to report suspicions of child abuse or neglect. There is no reason why members of the legal profession would not be able to manage a similar set of duties, if they were also permitted to make similar reports. The article has also suggested that, even if they are not legally required to report, lawyers should have the option to report. However, unless a vast improvement in the management of notifications occurs, both mandatory as well as optional reporting by any professional, has the potential to do harm to the very children that the legislation has aimed to protect.

10 Karen L Steinberg, Murray Levine and Howard J Doueck, 'Effects of Legally Mandated Child-Abuse Reports on the Therapeutic Relationship: A Survey of Psychotherapists'(1997) 67(1) American Journal of Orthopsychiatry 112.

11 Ibid. 